\title{
Indoxyl sulfate is associated with mortality after AKI - more evidence needed!
}

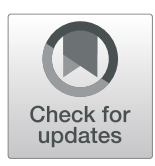

Steven Menez ${ }^{1,2,3}$, Mohamad Hanouneh ${ }^{1,4}$, Tariq Shafi ${ }^{1,5}$ and Bernard G. Jaar ${ }^{1,2,3,4^{*}}$

\begin{abstract}
Patients who develop acute kidney injury (AKI) have significantly higher short-term outcomes including in-hospital mortality. The development of AKI has been associated with long-term consequences including progression to chronic kidney disease (CKD) and higher rates of cardiovascular disease (CVD) and mortality. In recent years there has been a growing push for the discovery of novel methods to diagnose AKI at earlier stages, and for an improvement in risk stratification and prognosis following AKI.

Wang and colleagues assessed the association of total serum indoxyl sulfate (IS) levels, a protein bound uremic toxin, with 90-day mortality after hospital-acquired AKI (HA-AKI). These authors found that serum IS levels were significantly elevated in patients with HA-AKI $(2.74 \pm 0.75 \mu \mathrm{g} / \mathrm{mL})$ compared to healthy subjects $(1.73 \pm 0.11 \mu \mathrm{g} / \mathrm{ml}$, $P<0.001)$ and critically ill patients $(2.46 \pm 0.35 \mu \mathrm{g} / \mathrm{ml}, P=0.016)$.

The mechanisms of this relationship remain unclear, with a limited understanding of cause-specific mortality associated with either the high or low-IS group. One limitation of this current study is an understanding of the acceptable or expected higher level in IS during episodes of AKI. IS levels remained persistently elevated at day 7 compared to $\beta 2$-microglobulin and serum creatinine which were both lower at 7 days. It is unclear, however, if levels of $\beta 2$-microglobulin and serum creatinine were lower for other reasons, such as if any patients with AKI required dialysis.

This work provides an important addition to the field of AKI research, specifically in the evaluation of readily measurable biomarkers and outcomes after AKI. Moving forward, further validation in studies of acute kidney injury are needed to develop a better understanding of IS levels at the time of AKI diagnosis and trends during the course of AKI.
\end{abstract}

Keywords: AKI, Mortality, Risk factors, Indoxyl sulfate

\section{Commentary}

Acute kidney injury (AKI) is a major public health burden that affects millions of people globally every year [1-3]. Among hospitalized patients, various studies have reported an annual incidence of AKI ranging between 20 and $25 \%$, with rates exceeding $50 \%$ in the intensive care unit [4-6]. Patients with AKI have significantly higher in-hospital mortality, with increased resource utilization, compared to hospitalized patients who do not experience AKI $[1,7]$. Further, the development of AKI has

\footnotetext{
* Correspondence: bjaar@jhmi.edu

${ }^{1}$ Division of Nephrology, Department of Medicine, Johns Hopkins University School of Medicine, 1830 E. Monument Street, Suite 416, Baltimore, MD 21287, USA

2Department of Epidemiology, Johns Hopkins Bloomberg School of Public Health, 615 N. Wolfe Street, Baltimore, MD 21205, USA

Full list of author information is available at the end of the article
}

been associated with long-term consequences including progression to chronic kidney disease (CKD), higher rates of cardiovascular disease (CVD), and increased mortality [8-10].

It is widely recognized that standard methods used to diagnose AKI, including serum creatinine and urine output, can potentially lead to a delay in diagnosis and sometimes misdiagnosis of AKI [11, 12]. Therefore, in recent years there has been a growing push for the discovery of novel methods to diagnose AKI at earlier stages and improve both risk stratification and prognosis following AKI. Consequently, there has been a significant increase in the evaluation of novel urinary or blood biomarkers of kidney injury during the period of, and following episodes of AKI [13-15].

(c) The Author(s). 2019 Open Access This article is distributed under the terms of the Creative Commons Attribution 4.0 International License (http://creativecommons.org/licenses/by/4.0/), which permits unrestricted use, distribution, and 
Wang et al. previously evaluated the association between serum pre-albumin levels with outcomes after hospital-acquired AKI [16]. In their prior study using the same population cohort, the authors noted that relatively lower serum pre-albumin levels at the time of AKI diagnosis, as well as a relatively larger change in pre-albumin level over the course of 7 days, was associated with a significantly increased risk of 90-day mortality. In this article, Wang and colleagues assessed the association of total serum indoxyl sulfate (IS) levels, a protein bound uremic toxin, with 90-day mortality after hospital-acquired AKI (Fig. 1).

One major strength of this current study is the choice of IS, a protein-bound uremic toxin, and its association with 90-day mortality, given the biological plausibility of its role in the development of, and clinical course after, AKI noted in several studies. Protein-bound uremic toxins have been shown in patients with CKD to be associated with worse outcomes [17]. As the authors describe, IS is an end product of metabolism of dietary tryptophan, levels of which can be significantly elevated in the setting of CKD [18]. IS may play a central role in inflammation and endothelial cell injury in the setting of AKI $[19,20]$. Murine studies have elucidated the role of increasing IS levels with a subsequent rise in inflammatory markers such as Interleukin 1 beta (IL-1 $\beta$ ), phosphorylation of Mitogen-Activated Protein Kinase (MAPK), and activation of Nuclear Factor kappa-lightchain-enhancer of activated B cells (NF-kB) and Activator Protein 1 (AP-1). IS may prime endothelial cells for inflammation, with a second hit leading to endothelial cell injury, ultimately resulting in kidney injury [19].

However, it is still unclear whether IS serves as a direct toxin or could be an indicator, instead, of other unknown toxins. An elevated serum level of IS may itself be due to impaired clearance of this solute by tubular secretion in the setting of tubular injury and downregulation of organic anion transporters (OATs), but the association between IS level and clinical outcomes is certainly more complex. In the setting of sepsis in particular, other factors may lead to a higher production of IS such as changes in a patient's microbiome from antibiotics [21]. Prior research has shown that short-term mortality following AKI can be due to factors not directly related to AKI such as older age, other organ dysfunction, and coagulopathy [22, 23].

One limitation of this current study is an understanding of the acceptable or expected elevation in IS during episodes of AKI. For their primary analyses the authors used the mean value of $2.74 \mu \mathrm{g} / \mathrm{mL}$ in patients with AKI, significantly higher than the mean level in healthy subjects $(1.73 \mu \mathrm{g} / \mathrm{mL} ; p<0.001)$. The authors appropriately note that this was higher than in critically ill patients without AKI $(2.46 \mu \mathrm{g} / \mathrm{mL} ; p=0.02)$ but significantly lower than in patients with CKD $(3.07 \mu \mathrm{g} / \mathrm{mL}, p<$ 0.001). In their Cox regression models, the authors analyze IS dichotomously as well as continuously and show a significantly increased risk of 90-day mortality with higher levels. While the authors adjust for many potential confounders in their modeling, it would be worth evaluating the how these associations with IS and mortality compare against a more precise measure of kidney function, such as dynamic GFR in the setting of AKI [24].

Another area of uncertainty in this study is the course of the patients during and after hospitalization. The authors argue that IS levels remained persistently elevated at day 7 in 89 patients in their cohort, compared to $\beta 2$ microglobulin and serum creatinine which were both lower at 7 days, and that overall elevated IS levels may more accurately reflect kidney injury. It is unclear, however, if levels of $\beta 2$-microglobulin and serum creatinine were lower for other reasons, such as if any patients with AKI required dialysis. The authors rightly point out in their limitations that there are no data regarding urine output and cause of death. While a higher overall mortality in patients with elevated IS level following AKI was clearly observed, greater clarification into the cause of death is also warranted.

This work provides an important addition to the field of AKI research, specifically in the evaluation of readily measurable biomarkers and outcomes after AKI. As the

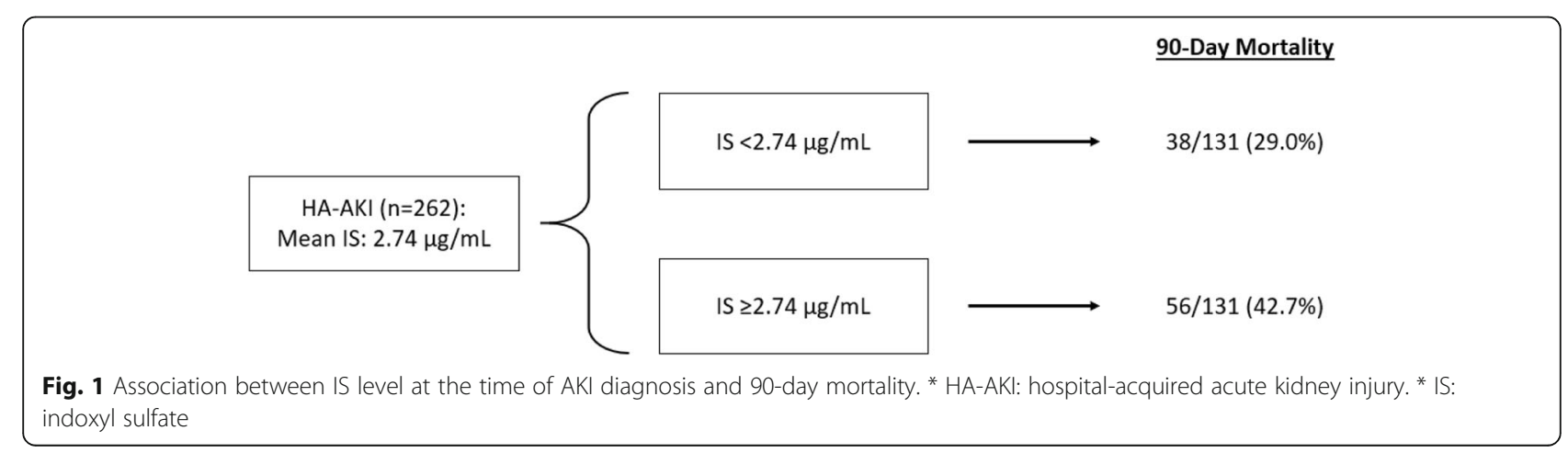


authors have shown, the use of IS was more clearly associated with mortality than either serum creatinine or $\beta 2$ microglobulin. Moving forward, further validation in studies of AKI are needed to develop a better understanding of IS levels at the time of AKI diagnosis and trends during the course of AKI. Ultimately, however, the question of utility must be addressed prior to any clinical implementation. Previously, the association between IS and inflammation in the CKD population led to increased attention as a potential therapeutic target in slowing CKD progression $[25,26]$. However, despite research showing an effective reduction in IS levels with drugs such as AST-120 in patients with CKD and ESRD, no benefit has been demonstrated in the use of AST-120 with all-cause and cardiovascular mortality [27-29]. While these data are not convincing in the CKD population, reduction of IS in the setting of AKI has yet to be explored.

In summary, Wang and colleagues describe the association between elevated IS level and 90-day mortality after hospital-acquired AKI. The mechanisms of this relationship remain unclear however, with a limited understanding of cause-specific mortality associated with either the high or low-IS group. Further, other major cardiovascular and kidney-related outcomes were not explored but warrant additional investigation. Findings of this study will need to be validated and if confirmed, the use of IS may hold significant potential for clinical use..

\section{Abbreviations}

AKI: Acute kidney injury; AP-1: Activator protein 1; CKD: Chronic kidney disease; CVD: Cardiovascular disease; ESKD: End stage kidney disease; IL1 $\beta$ : Interleukin 1 beta; IS: Indoxyl sulfate; MAPK: Mitogen-activated protein kinase; NF-kB: Nuclear factor kappa-light-chain-enhancer of activated B cells; OAT: Organic anion transporter

\section{Acknowledgements}

The authors declare that they have no relevant financial interests.

\section{Authors' contributions}

SM was primarily responsible for the first draft of the manuscript. $\mathrm{MH}, \mathrm{TS}$, and BGJ were all involved in the editing process. BGJ gave final approval for this commentary's submission. All authors read and approved the final manuscript.

\section{Funding}

SM receives funding support through $\mathrm{NIH}$ T32 training grant:

5T32HL007024-44 (PI: Dr. Josef Coresh). TS is supported by NHLBI (R01-HL132372), NINR (R01-DK-117388), AHRQ (HHSA290201500006I), and The Bower Foundation.

\section{Availability of data and materials} N/A

\section{Ethics approval and consent to participate}

N/A

\section{Consent for publication}

N/A

\section{Competing interests}

Bernard Jaar and Tariq Shafi are editorial board members of the journal BMC Nephrology but played no role in the handling of this manuscript. All other authors declare that they have no relevant competing interests.

\section{Author details}

'Division of Nephrology, Department of Medicine, Johns Hopkins University School of Medicine, 1830 E. Monument Street, Suite 416, Baltimore, MD 21287, USA. ${ }^{2}$ Department of Epidemiology, Johns Hopkins Bloomberg School of Public Health, 615 N. Wolfe Street, Baltimore, MD 21205, USA. ${ }^{3}$ Welch Center for Prevention, Epidemiology and Clinical Research, Johns Hopkins University, 2024 E. Monument Street, Baltimore, MD 21205, USA. ${ }^{4}$ Nephrology Center of Maryland, 5601 Loch Raven Boulevard, Suite 3 North, Baltimore, MD 21239, USA. ${ }^{5}$ Division of Nephrology, Department of Medicine, University of Mississippi Medical Center, Jackson, MS, USA.

Received: 5 June 2019 Accepted: 17 July 2019

Published online: 26 July 2019

\section{References}

1. Chertow GM, Burdick E, Honour M, Bonventre JV, Bates DW. Acute kidney injury, mortality, length of stay, and costs in hospitalized patients. J Am Soc Nephrol. 2005;16(11):3365-70.

2. Susantitaphong P, Cruz DN, Cerda J, Abulfaraj M, Alqahtani F, Koulouridis I, Jaber BL. Acute kidney injury advisory Group of the American Society of N: world incidence of AKl: a meta-analysis. Clin J Am Soc Nephrol. 2013;8(9): 1482-93.

3. Negi S, Koreeda D, Kobayashi S, Yano T, Tatsuta K, Mima T, Shigematsu T, Ohya M. Acute kidney injury: epidemiology, outcomes, complications, and therapeutic strategies. Semin Dial. 2018;31(5):519-27.

4. Taber SS, Mueller BA. Drug-associated renal dysfunction. Crit Care Clin. 2006; 22(2):357-74 viii.

5. Case J, Khan S, Khalid R, Khan A. Epidemiology of acute kidney injury in the intensive care unit. Crit Care Res Prac. 2013;2013:479730.

6. Singbartl K, Kellum JA. AKI in the ICU: definition, epidemiology, risk stratification, and outcomes. Kidney Int. 2012;81(9):819-25.

7. Zeng X, McMahon GM, Brunelli SM, Bates DW, Waikar SS. Incidence, outcomes, and comparisons across definitions of AKI in hospitalized individuals. Clin J Am Soc Nephrol. 2014:9(1):12-20.

8. Li SY, Chen JY, Yang WC, Chuang CL. Acute kidney injury network classification predicts in-hospital and long-term mortality in patients undergoing elective coronary artery bypass grafting surgery. Eur J Cardiothorac Surg. 2011;39(3):323-8.

9. Parikh CR, Coca SG, Thiessen-Philbrook H, Shlipak MG, Koyner JL, Wang Z, Edelstein CL, Devarajan P, Patel UD, Zappitelli M, et al. Postoperative biomarkers predict acute kidney injury and poor outcomes after adult cardiac surgery. J Am Soc Nephrol. 2011;22(9):1748-57.

10. Odutayo A, Wong CX, Farkouh M, Altman DG, Hopewell S, Emdin CA, Hunn $\mathrm{BH}$. AKI and long-term risk for cardiovascular events and mortality. J Am Soc Nephrol. 2017;28(1):377-87.

11. Ostermann M. Diagnosis of acute kidney injury: kidney disease improving global outcomes criteria and beyond. Curr Opin Crit Care. 2014;20(6):581-7.

12. Vijayan A, Faubel S, Askenazi DJ, Cerda J, Fissell WH, Heung M, Humphreys $B D$, Koyner JL, Liu KD, Mour G, et al. Clinical use of the urine biomarker [TIMP-2] x [IGFBP7] for acute kidney injury risk assessment. Am J Kidney Dis. 2016;68(1):19-28.

13. Coca SG, Garg AX, Thiessen-Philbrook H, Koyner JL, Patel UD, Krumholz HM, Shlipak MG, Parikh CR, Consortium T-A. Urinary biomarkers of AKI and mortality 3 years after cardiac surgery. J Am Soc Nephrol. 2014; 25(5):1063-71.

14. Alge $J L$, Arthur JM. Biomarkers of AKI: a review of mechanistic relevance and potential therapeutic implications. Clin J Am Soc Nephrol. 2015;10(1):147-55.

15. Parikh CR, Puthumana J, Shlipak MG, Koyner JL, Thiessen-Philbrook H, McArthur E, Kerr K, Kavsak P, Whitlock RP, Garg AX, et al. Relationship of kidney injury biomarkers with long-term cardiovascular outcomes after cardiac surgery. J Am Soc Nephrol. 2017;28(12):3699-707.

16. Wang W, Pan Y, Tang X, Hao G, Xie Y, Ma S, Luo J, Guo D, Ding F. Serum prealbumin and its changes over time are associated with mortality in acute kidney injury. Sci Rep. 2017;7:41493. 
17. Liabeuf S, Cheddani L, Massy ZA. Uremic toxins and clinical outcomes: the impact of kidney transplantation. Toxins (Basel). 2018;10(6).

18. Niwa T. Uremic toxicity of indoxyl sulfate. Nagoya J Med Sci. 2010;72(1-2):1-11.

19. Shen WC, Liang CJ, Huang TM, Liu CW, Wang SH, Young GH, Tsai JS, Tseng YC, Peng YS, Wu VC, et al. Indoxyl sulfate enhances IL-1 beta-induced Eselectin expression in endothelial cells in acute kidney injury by the ROS/ MAPKs/NFkappaB/AP-1 pathway. Arch Toxicol. 2016;90(11):2779-92.

20. Wu VC, Young GH, Huang PH, Lo SC, Wang KC, Sun CY, Liang CJ, Huang $\mathrm{TM}$, Chen JH, Chang FC, et al. In acute kidney injury, indoxyl sulfate impairs human endothelial progenitor cells: modulation by statin. Angiogenesis. 2013;16(3):609-24.

21. Yang $C Y$, Tarng DC. Diet, gut microbiome and indoxyl sulphate in chronic kidney disease patients. Nephrology (Carlton, Vic). 2018;23(Suppl 4):16-20.

22. Levy EM, Viscoli CM, Horwitz RI. The effect of acute renal failure on mortality. A cohort analysis. Jama. 1996;275(19):1489-94.

23. Rhee H, Jang KS, Park JM, Kang JS, Hwang NK, Kim IY, Song SH, Seong EY, Lee DW, Lee SB, et al. Short- and long-term mortality rates of elderly acute kidney injury patients who underwent continuous renal replacement therapy. PLoS One. 2016;11(11):e0167067.

24. O'Sullivan ED, Doyle A. The clinical utility of kinetic glomerular filtration rate Clin Kidney J. 2017;10(2):202-8.

25. Kaminski TW, Pawlak K, Karbowska M, Mysliwiec M, Pawlak D. Indoxyl sulfate - the uremic toxin linking hemostatic system disturbances with the prevalence of cardiovascular disease in patients with chronic kidney disease. BMC Nephrol. 2017;18(1):35-017-0457-0451.

26. Barisione C, Ghigliotti G, Canepa M, Balbi M, Brunelli C, Ameri P. Indoxyl sulfate: a candidate target for the prevention and treatment of cardiovascular disease in chronic kidney disease. Curr Drug Targets. 2015; 16(4):366-72.

27. Lee CT, Hsu CY, Tain YL, Ng HY, Cheng BC, Yang CC, Wu CH, Chiou TT, Lee YT, Liao SC. Effects of AST-120 on blood concentrations of protein-bound uremic toxins and biomarkers of cardiovascular risk in chronic dialysis patients. Blood Purif. 2014;37(1):76-83.

28. Shafi T, Sirich TL, Meyer TW, Hostetter TH, Plummer NS, Hwang S, Melamed ML, Banerjee T, Coresh J, Powe NR. Results of the HEMO study suggest that p-cresol sulfate and indoxyl sulfate are not associated with cardiovascular outcomes. Kidney Int. 2017;92(6):1484-92.

29. Cha RH, Kang SW, Park CW, Cha DR, Na KY, Kim SG, Yoon SA, Han SY, Chang JH, Park SK, et al. A randomized, controlled trial of Oral intestinal sorbent AST-120 on renal function deterioration in patients with advanced renal dysfunction. Clin J Am Soc Nephrol. 2016;11(4):559-67.

\section{Publisher's Note}

Springer Nature remains neutral with regard to jurisdictional claims in published maps and institutional affiliations.

Ready to submit your research? Choose BMC and benefit from:

- fast, convenient online submission

- thorough peer review by experienced researchers in your field

- rapid publication on acceptance

- support for research data, including large and complex data types

- gold Open Access which fosters wider collaboration and increased citations

- maximum visibility for your research: over $100 \mathrm{M}$ website views per year

At BMC, research is always in progress.

Learn more biomedcentral.com/submissions 